\title{
Technical Assessment of Hybrid HVDC Circuit Breaker Components under M-HVDC Faults
}

\author{
Saqib Khalid ${ }^{1}$, Ali Raza ${ }^{2, *} \mathbb{*}$, Umar Alqasemi ${ }^{3}$, Nebras Sobahi ${ }^{3}\left(\right.$, Muhammad Zain Yousaf ${ }^{4}($, \\ Ghulam Abbas ${ }^{1}$ (D) and Mohsin Jamil ${ }^{5}$ (D) \\ 1 Department of Electrical Engineering, The University of Lahore, Lahore 54000, Pakistan; \\ saqib.khalid@ee.uol.edu.pk (S.K.); ghulam.abbas@ee.uol.edu.pk (G.A.) \\ 2 Department of Electrical Engineering, University of Engineering and Technology, Lahore 54000, Pakistan \\ 3 Department of Electrical and Computer Engineering, King Abdulaziz University, Jeddah 21589, Saudi Arabia; \\ ualqasemi@kau.edu.sa (U.A.); nsobahi@kau.edu.sa (N.S.) \\ 4 School of Electrical Engineering, Guangxi University, Nanning 530600, China; mzainy1@gmail.com \\ 5 Faculty of Engineering and Applied Science, Memorial University of Newfoundland, \\ St. John's, NL A1B 3X5, Canada; mjamil@mun.ca \\ * Correspondence: a.raza@uet.edu.pk
}

check for updates

Citation: Khalid, S.; Raza, A.; Alqasemi, U.; Sobahi, N.; Yousaf, M.Z.; Abbas, G.; Jamil, M. Technical Assessment of Hybrid HVDC Circuit Breaker Components under M-HVDC Faults. Energies 2021, 14, 8148. https://doi.org/10.3390/en14238148

Academic Editor: Mario Marchesoni

Received: 3 November 2021

Accepted: 30 November 2021

Published: 5 December 2021

Publisher's Note: MDPI stays neutral with regard to jurisdictional claims in published maps and institutional affiliations.

Copyright: (c) 2021 by the authors. Licensee MDPI, Basel, Switzerland. This article is an open access article distributed under the terms and conditions of the Creative Commons Attribution (CC BY) license (https:// creativecommons.org/licenses/by/ $4.0 /)$.

\begin{abstract}
One of the technical challenges that needs to be addressed for the future of the multiterminal high voltage direct current (M-HVDC) grid is DC fault isolation. In this regard, HVDC circuit breakers (DCCBs), particularly hybrid circuit breakers (H-DCCBs), are paramount. The $\mathrm{H}$ $\mathrm{DCCB}$, proposed by the ABB, has the potential to ensure a reliable and safer grid operation, mainly due to its millisecond-level current interruption capability and lower on-state losses as compared to electromechanical and solid-state based DCCBs. This paper aims to study and evaluate the operational parameters, e.g., electrical, and thermal stresses on the IGBT valves and energy absorbed by the surge arrestors within H-DCCB during different DC fault scenarios. A comprehensive set of modeling requirements matching with operational conditions are developed. A meshed fourterminal HVDC test bench consisting of twelve H-DCCBs is designed in PSCAD/EMTDC to study the impacts of the M-HVDC grid on the operational parameters of H-DCCB. Thus, the system under study is tested for different current interruption scenarios under a (i) low impedance fault current and (ii) high impedance fault current. Both grid-level and self-level protection strategies are implemented for each type of DC fault.
\end{abstract}

Keywords: electrical and thermal stresses; hybrid HVDC circuit breaker; multi-terminal HVDC transmission systems; HVDC grid protection

\section{Introduction}

Recently there has been an increased interest in developing a voltage source converter (VSC) based on multi-terminal high voltage direct current (M-HVDC) transmission grids. For this purpose, HVDC circuit breakers (DCCBs) are considered to be a vital component responsible for interrupting and isolating the DC fault current [1]. Owing to the low damping of the DC fault current in an HVDC grid, the initial rate of the rising fault current can reach the $\mathrm{kA} / \mathrm{ms}$ range [2]. This results in various electrical and thermal stresses to be developed on the DCCB components and branches. These stresses may compromise, not only the DCCB's operation, but also affect its operational performance. Studying these electrical, thermal, and energy absorption stresses would highlight the states of DCCB's components under different DC fault conditions.

A multi-terminal HVDC (M-HVDC) grid system can be realized through the interconnection of various HVDC substations. However, most of the present HVDC systems consist of line commutated converters (LCC) forming point-to-point connections only. Though only a few M-HVDC systems exist today, their development is hugely restricted; this is 
mainly because of the lack of DC grid protection systems, particularly fast-acting high voltage DC circuit breakers (DCCBs) [1].

Presently, no fast-acting, low loss, and reliable DC breakers capable of isolating the DC faults without de-energizing the entire HVDC grid are commercially available [3]. DCCBs are considerably more complex and costly than conventional AC breakers. This is primarily because of two reasons: (i) the current absence of a natural zero-crossing in DC, necessary to extinguish the fault current. Thus, a DCCB must create an artificial current zero-crossing; and (ii) due to a DC system's low impedance, the DC fault current rises sharply, to nearly ten times its rated current within just a few milliseconds. This leads to significant differences between the testing requirements of HVDC breakers.

In most cases, the DC faults in a point-to-point HVDC system are handled using AC side breakers. The protection requirements of VSC-based M-HVDC grid vary significantly from LCC-based point to point HVDC grids. Under a DC fault, a VSC in an M-HVDC grid inherently acts as an uncontrolled diode bridge, thus feeding the DC fault from the AC side [2]. Additionally, considering the effect of the natural low impedance of a DC grid, the fault current rises to a substantially high magnitude in just the first few milliseconds of fault inception. Conventional AC circuit breakers have an operating time of 20-100 ms. Thus, AC circuit breakers are rendered useless for operation in future VSC-based M-HVDC grids.

Three main types of DCCB technologies have been developed, namely (i) mechanical DCCB [4], (ii) solid-state DCCB [5-7], and (iii) hybrid DCCB [8-11]. The mechanical DCCB can conduct a large current with lower on-state losses. However, the operating time of even the most advanced type of mechanical DCCB is still high, at 5-10 ms [12]. On the other hand, solid-state DCCB utilizes hundreds of power electronic devices, typically IGBTs, for the DC fault current interruption. The operating times for this type of DCCBs are in the range of 1-3 ms [13]. However, despite their shorter operating time, they offer high on-state losses [14]. Lastly, the hybrid breaker combines the qualities of its predecessors to achieve shorter operating times, between $2-5 \mathrm{~ms}$, and lower on-state losses than the solid-state DCCBs [3]. This makes H-DCCB the prime candidate for DC fault interruption for future M-HVDC systems.

However, to the best of the author's knowledge, no commercially matured H-DCCBs are currently available, except for a few industrial concepts and prototypes proposed by ABB, Alston, etc. $[15,16]$. Nonetheless, there is a need to study the performance of hybrid breakers under realistic service conditions to pave the way for future VSC-based M-HVDC grids [17-19]. In this paper, the impacts of the M-HVDC grid on ABB hybrid breakers are studied.

Researches are conducted to highlight various components and characteristics of different H-DCCB topologies $[15,20]$. However, these studies are limited to a specific DC test circuit only [21]. This is because the modeling, design, control, and construction of H-DCCB are yet to be standardized. Hence, the modeling and testing of H-DCCB under practical service conditions, such as in an M-HVDC system, are not studied.

Various test circuits and methods have been proposed in the literature for testing high voltage DCCBs. The authors of [22-24] suggested a low-frequency AC short circuit generator, which generates a constant unipolar quasi-DC current for a short time interval. This method can effectively test the DCCB's current interruption and energy absorption capabilities under fault conditions. However, its disadvantage is that backup protection must be provided if the DCCB that is under test fails to prevent damage to the test equipment. Additionally, a high voltage DCCB undergoes system-level voltage immediately after the current interruption process under realistic conditions. Therefore, in this type of DCCB testing, a separate DC voltage source is required to supply the DC voltage to mimic the dielectric stresses a DCCB undergoes subsequently after a current interruption process [24]. However, the precise instant at which dielectric pressure is applied through the DC voltage source is difficult to accurately determine in advance, due to varying operational characteristics of high voltage DCCBs. 
The authors of [21] performed a comparative study of several test circuits, including pre-charged capacitive, pre-charged inductive, and variable frequency short circuit generators for high voltage DCCBs. It was concluded that neither the capacitor nor inductor-based charged circuits could provide the required discharge time, eventually under-stressing the DCCB under test. This is because these test circuits usually generate low peak quasi-DC currents to test the current interruption capability of a high voltage DCCB. A similar study utilizing charged capacitors' and reactors' test circuits have been carried by the authors of $[9,25]$. This inductor and capacitor (LC) based resonant test circuit can generate constant current for a reasonably long-time interval to provide realistic DC fault current scenarios. However, these test circuits may use large pre-charged capacitors to apply sufficient voltage stress on the DCCB test [16]. In addition, scaled-down versions of the individual H-DCCB sub-module were tested mainly for the current interruption and voltage stress only. Zheng $\mathrm{Xu}$ et al. studied the current interruption and voltage and the withstanding capability of conventional MOSA-based H-DCCB and novel H-DCCB compromising capacitors in the energy absorption branch [26]. It was concluded that the novel topology decreased the conduction losses and the number of IGBT valves required to interrupt and withstand the current and voltage of similar magnitudes compared to conventional H-DCCB. However, no energy or thermal stresses were studied on the individual IGBT valves in all of these studies.

In $[27,28]$, DCCBs are directly tested in service conditions for close-in fault tests, remote fault tests, and load breaking tests. However, these types of tests are costly and not commercially attractive. Some studies modified AC test circuits to create synthetic test circuits for DCCBs [29-31]. This method not only saves investment costs but is also capable of generating a higher peak discharge current with a longer discharge time. However, to the best of the authors' knowledge, studies related to electrical and thermal stresses on various H-DCCB components like IGBT valves and surge arrestors, especially during the energy absorption stage, are not carried out in all these test circuits. A typical DCCB test circuit needs to handle significant energy dissipation, apart from focusing on interrupting the DC fault current [21]. DCCBs and their test circuits are still not mature and are evolving. It is still ambiguous whether the test circuits proposed in the literature can effectively model the operational stresses on H-DCCB like those in experimental conditions [32].

Therefore, this paper highlights the electrical and thermal stresses on hybrid breaker components, IGBT valves, and surge arrestors under different DC fault conditions. Thus, the demonstration of H-DCCB in the meshed four-terminal HVDC system for studying and investigating the operational parameters will play a significant role in realizing a future M-HVDC system. Both grid-level and self-level protection strategies are applied to study the electrical and thermal stress in the case of: (i) low impedance; and (ii) high impedance DC faults.

\section{M-HVDC Test System Model}

A single-line diagram of the proposed VSC-based four-terminal HVDC grid test system is shown in Figure 1. The proposed test system consists of a symmetrical bipolar transmission line configuration, considering positive and negative DC voltages. H-DCCBs are connected at each end of the transmission line for protection against DC faults. A total of $12 \mathrm{H}$-DCCBs are utilized in the test system. In addition, a series reactor $(100 \mathrm{mH})$ is connected with each H-DCCB to limit the rate of rising of the DC fault current. Lengths for the DC cables C14, C12, C34, and C23 are $300 \mathrm{~km}, 100 \mathrm{~km}, 100 \mathrm{~km}$, and $300 \mathrm{~km}$, respectively. The grid test system utilizes a $\pm 400 \mathrm{kV}$ HVDC link. The operational parameters for the M-HVDC grid system are listed in Table 1. 


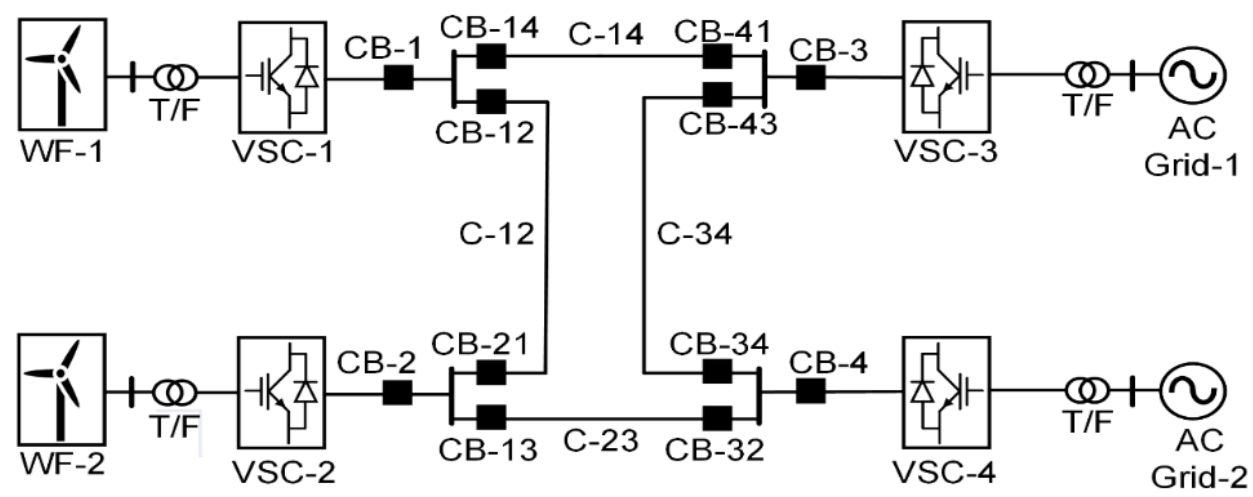

Figure 1. M-HVDC grid system for testing H-DCCB.

Table 1. Main Parameters of M-HVDC Test System.

\begin{tabular}{clc}
\hline Side & \multicolumn{1}{c}{ Parameter } & Value \\
\hline & M-HVDC grid voltage & $400 \mathrm{kV}$ \\
& Length of DC-cable 12 & $100 \mathrm{~km}$ \\
DC & Length of DC-cable 14 & $300 \mathrm{~km}$ \\
& Length of DC-cable 23 & $300 \mathrm{~km}$ \\
& Length of DC-cable 34 & $100 \mathrm{~km}$ \\
\hline & Line-Line system voltage & $240 \mathrm{kV}$ \\
& Rated power VSC-1 & $400 \mathrm{MW}$ \\
& Rated power VSC-2 & $800 \mathrm{MW}$ \\
& Rated power VSC-3 & $-500 \mathrm{MW}$ \\
& Rated power VSC-4 & $-700 \mathrm{MW}$ \\
\hline
\end{tabular}

All VSCs are modeled using half-bridge multi-modular converters (MMCs) [33]. $\mathrm{P}-\mathrm{V}_{\mathrm{ac}}$ control is employed on offshore converter stations (VSC-1 and VSC-2) to maintain constant active power throughout the M-HVDC grid. This control also provides AC voltage regulation at the point of common coupling (PCC) [1]. Lastly, $\mathrm{P}-\mathrm{V}_{\mathrm{dc}}$ droop control and reactive power control settings are implemented on the onshore converter stations (VSC-3 and VSC-4) [34]. This control mode ensures constant DC link voltages and regulates the reactive power exchange between converters and $\mathrm{AC}$ grids.

The bidirectional H-DCCB parameters and their component ratings are listed in Table 2. 5SNA 2000K450300 IGBT module is chosen for load commutation switch (LCS) and main breaker $(\mathrm{MB})$. The LCS comprises a $3 \times 3$ IGBT module configuration, whereas MB consists of 200 connected IGBT modules divided into four stacks.

Table 2. Main Parameters of H-DCCB.

\begin{tabular}{lc}
\hline \multicolumn{1}{c}{ Parameter } & Value \\
\hline Rated DC voltage $\left(\mathrm{V}_{\mathrm{dc}-\mathrm{R}}\right)$ & $400 \mathrm{kV}$ \\
Rated DC current $\left(\mathrm{I}_{\mathrm{dc}-\mathrm{R}}\right)$ & $1.80 \mathrm{kA}$ \\
Rated breaking current $\left(\mathrm{I}_{\mathrm{dc}-\mathrm{B}}\right)$ & $11.5 \mathrm{kA}$ \\
Current limiting reactor & $150 \mathrm{mH}$ \\
Number of series $\times$ parallel IGBT in LCS & $3 \times 3$ \\
Number of series IGBT in MB $\left(\mathrm{N}_{\mathrm{s}}\right)$ & 200 \\
Rated breaking current for RCB and UFA & $0.01 \mathrm{kA}$ \\
\hline
\end{tabular}

\section{H-DCCB Proposed by the ABB}

The schematic of H-DCCB as proposed by ABB is illustrated in Figure 2 [15]. This general topology comprises three parallel branches: the load branch, the main breaker (MB) branch, and the energy absorption branch. A slow mechanical switch in the form of a residual circuit breaker (RCB) is inserted in the series before the main assembly of the hybrid breaker. The load branch consists of an ultra-fast mechanical actuator (UFA), in 
series with an IGBT-based load commutation switch (LCS). In contrast, the main breaker branch comprises sections of series and parallel combinations of IGBT valves.

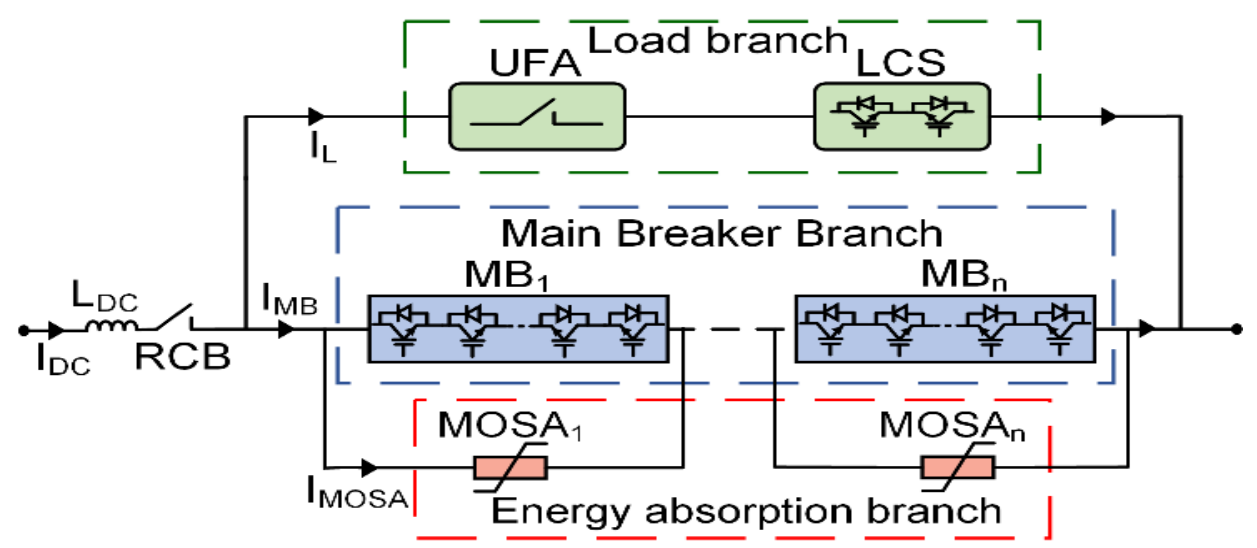

Figure 2. Schematic of H-DCCB as proposed by ABB.

The metal oxide surge arrestors (MOSA) in this H-DCCB are dedicated to absorbing the magnetic energy stored in the system inductances. Multiple MOSA blocks are stacked in the energy absorption branch in parallel with the IGBT valves of MB, ensuring equal current distribution and efficient energy handling capability. In addition, MOSAs limit transient interruption voltages (TIV) during the current interruption process [35].

The use of semiconductor switches in H-DCCB offers the required high operation speed in the range of a few milliseconds. Additionally, on-state losses are significantly reduced because the current does not pass through the IGBT valves of MB unless a fault occurs.

Initially, under normal conditions, the IGBT valves of LCS in an H-DCCB are in a closed state while $\mathrm{MB}$ is in an open state. Hence, during normal load conditions, the DC load current passes through the load branch only. The corresponding current waveform of $\mathrm{H}-\mathrm{DCCB}$, as proposed by $\mathrm{ABB}$, is shown in Figure 3 [15]. The general strategy for DC fault isolation using an H-DCCB consists of the following sequence of events [36]:

Step 1: During normal operating conditions, the IGBT valves of LCS are closed while IGBT valves of MB are opened. Due to the low impedance of the load branch, most of the load current passes through it, as shown in Figure 4a.

Step 2: At time $t_{1}$, a short circuit fault occurs, and the DC fault current rises rapidly at the DC side of the VSC. As the DC fault current reaches a set threshold (trip-value), a trip signal is issued at $t_{2}$. LCS is immediately opened, and the IGBT valve of the MB branch is turned ON, causing the fault current to commutate to the MB from the load branch. This procedure is generally referred to as the first commutation process, as shown in Figure $4 \mathrm{~b}$. This process triggers the opening of UFA as well.

Step 3: The contacts of UFA are fully separated within 2 ms [15], such that they can withstand and protect the LCS from transient interruption voltages. The IGBT valves in $\mathrm{MB}$ are then turned off at time $t_{3}$.

Step 4: The above action causes the DC fault current to commutate into the energy dissipation branch. Eventually, this DC fault current is dissipated through the counter voltages of the MOSA from time $t_{3}$ to $t_{4}$, as illustrated in Figure $4 c$.

Step 5: Most of the fault current is interrupted at this stage, and only a small leakage current pass through the MOSA. Finally, to prevent arrestors from thermal overload, the RCB is opened at $t_{4}$, as shown in Figure $4 d$. 


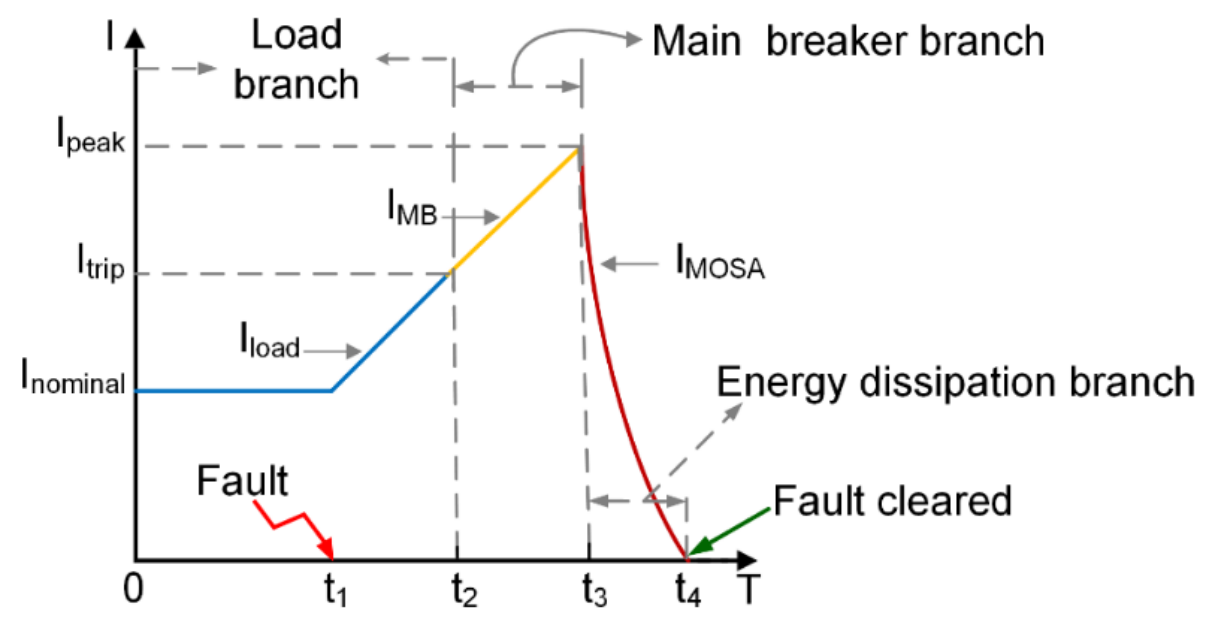

Figure 3. H-DCCB fault current interruption.

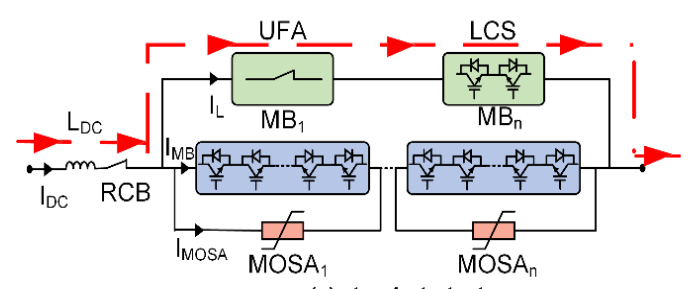

(a) step 1: $t_{1}<t<t_{2}$

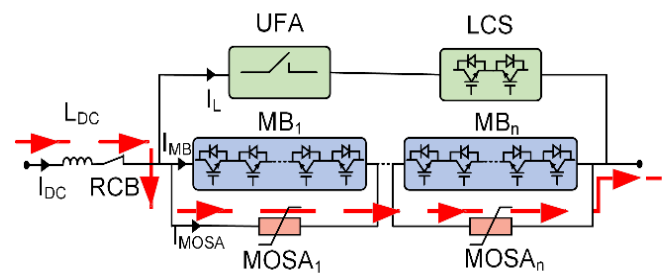

(c) step 3: $\mathrm{t}=\mathrm{t}_{3}$

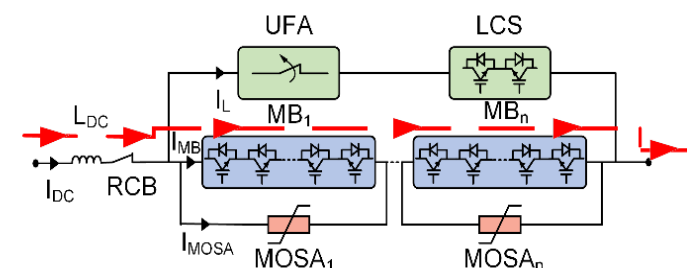

(b) step 2: $\mathrm{t}_{2}<\mathrm{t}<\mathrm{t}_{3}$

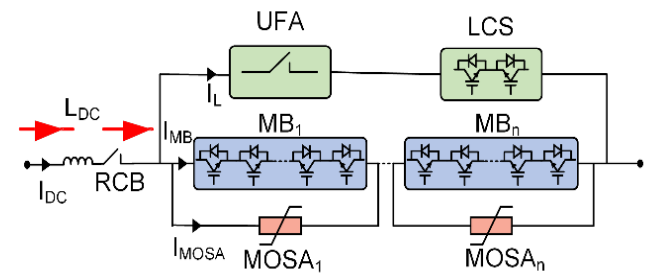

(d) step 3: $\mathrm{t}=\mathrm{t}_{4}$

Figure 4. H-DCCB fault current interruption sequence.

\section{H-DCCB Protection Flow Chart}

There are three primary levels of protection from which a trip signal can be issued to an ABB H-DCCB: grid-level protection, self-level protection, and driver-level protection, as illustrated in Figure 5 [37].

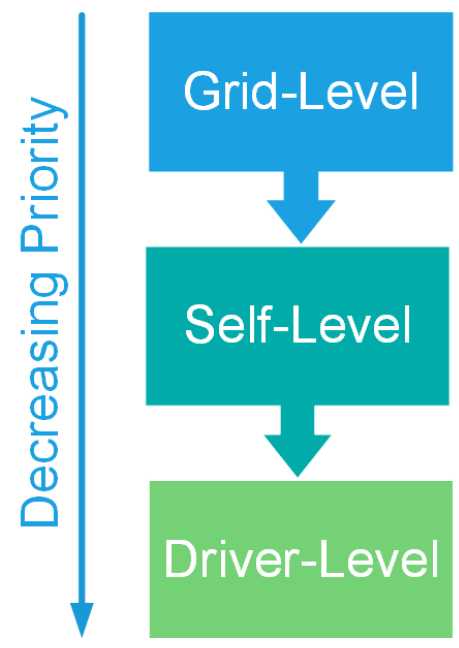

Figure 5. H-DCCB protection flow chart. 
In grid-level protection, the H-DCCB breaker initiates the tripping sequence on receiving the trip order from the M-HVDC grid protection system. However, in self-level protection, the H-DCCB starts the tripping sequence by itself. A self-level protection scheme is implemented if the grid-level protection fails to issue a trip command or if the temperature of the IGBT valve exceeds a certain threshold. In doing so, the breaker components are prevented from incurring any damage. Lastly, a driver-level protection scheme is also embedded in the IGBT valves of the load and MB branches. This protection scheme is activated once the DC fault current reaches the rated current of the IGBT valves, leading to the permanent destruction of the IGBT valves of LCS and the MB [38].

\section{Stress Analysis during DC Fault}

An H-DCCB must withstand the peak DC fault current and the TIV imposed by surge arrestors to successfully interrupt a DC fault current. This exposes the IGBT valves to current, voltage, energy absorption, and thermal stresses.

IGBT valves are the most sensitive and expensive component in an H-DCCB. Also, as the system rating increases, the cost for the IGBT valves increases proportionally. Therefore, studying the various critical stresses that the IGBT valves are exposed to during service conditions is essential.

\subsection{Voltage and Current Stresses}

$\mathrm{H}-\mathrm{DCCB}$ needs to withstand a voltage level more than the system voltage during a $\mathrm{DC}$ fault to reduce the fault current magnitude equal to or lesser than that of the residual current value in a short duration of time [3]. The IGBTs are connected in parallel with the surge arrestors in the main branch. Therefore, the maximum voltage stress that the IGBT valves are being subjected to is directly dependent on the clipping voltage level of these surge arrestors [39]. Generally, surge arrestors' clipping voltage should be below the voltage rating of the IGBT valves to prevent them from any overvoltage damage during the DC faults [40]. However, the IGBT valves must withstand up to 1.5 times the rated system voltage during the internal current commutation process [39]. The voltage stresses on each IGBT in MB can also be reduced through their appropriate paralleling and series interconnections [41]. Finally, once the fault is cleared, the breaker components are subjected to system-level voltages.

During fault current interruption, the IGBT valves of the LCS are subjected to voltage stress equal to the voltage drop across the MB branch, which is given by (1):

$$
\mathrm{V}_{\mathrm{LCS}}=\mathrm{N}_{\mathrm{S}} \mathrm{V}_{\text {ce(on) }}+\mathrm{N}_{\mathrm{S}} \mathrm{R}_{\mathrm{on}} \mathrm{I}_{\mathrm{f}(\max )}
$$

The on-state voltage $\left(\mathrm{V}_{\text {ce(on) }}\right)$, as well as the on-state resistance $\left(\mathrm{R}_{\mathrm{on}}\right)$ for each IGBT module, are assumed to be $2.6 \mathrm{~V}$ and $1.44 \mathrm{~m} \Omega$, while the maximum breaking current $\left(\mathrm{I}_{\mathrm{f}(\max )}\right)$ is $11.5 \mathrm{kA}$, respectively. Using (1), the voltage stress applied to the LCS valves is found to be $3.83 \mathrm{kV}$. Considering the individual module voltage rating of $4.5 \mathrm{kV}$, this voltage stress on the LCS valves is well below its rated voltage [42]. However, practically a $3 \times 3$ configuration of IGBT modules is used in LCS to provide adequate voltage and minimal power loss.

DC faults cause over-current stresses in IGBT modules. This occurs when current levels reach several times higher than the rated current carrying capacity of the IGBT module. This leads to accelerated aging of the module, as well as decreasing its lifetime and reliability. De-saturation of the IGBT valve may also occur during a DC fault, causing high conduction losses and severe overheating, leading to valve destruction [43].

Using a series current limiting reactor ensures that the fault current magnitude does not exceed the current rating of the components of H-DCCB. Assuming a $10 \%$ system over-voltage, the appropriate value of the current limiting reactor $\left(L_{R}\right)$ is dependent on the rated system voltage $\left(\mathrm{V}_{\mathrm{DC}}\right)$ as well as the rate of rising of the $\mathrm{DC}$ fault current $(\mathrm{di} / \mathrm{dt})$ [21] Hence, the value of the DC limiting reactor is determined as: 


$$
\mathrm{L}_{\mathrm{R}}=\frac{1.1 \mathrm{~V}_{\mathrm{DC}}}{(\mathrm{di} / \mathrm{dt})}
$$

Furthermore, the rate of the DC fault current is also influenced by various factors; the distance between the fault and the circuit breaker, the number of feeders connected to the closest bus and the breaker, and the type of DC transmission used within the M-HVDC grid [44].

\subsection{MOSA Energy Absorption Stress}

Apart from handling the voltage stress due to TIV, the other leading role of MOSA in an $\mathrm{H}-\mathrm{DCCB}$ is to bear the energy absorption stress during the current extinguishing process. Therefore, individual MOSA stacks may be arranged in parallel columns across each IGBT module. This ensures efficient energy absorption capacity and provides a greater degree of redundancy [35].

During the energy absorption stage, the rate at which the fault current decay is determined by the current limiting reactor and the clamping voltage of the MOSA ( $\mathrm{V}_{\text {MOSA }}$ ) across the breaker as given by (3) to (5) [25]:

$$
\mathrm{V}_{\mathrm{DC}}=\frac{1}{1.10}\left(\mathrm{~V}_{\mathrm{R}}+\mathrm{V}_{\mathrm{CB}}\right)
$$

In (3), $V_{R}$ represents the voltage across the reactor induced during the $D C$ fault. Additionally, $\mathrm{V}_{\mathrm{CB}}$ is the voltage across the breaker terminals before the current is commutated to the energy absorption branch, i.e., the first commutation process.

Once the DC fault current commutates to the energy absorption branch, the breaker terminal voltage is limited by the clamping voltage of the MOSA, $\mathrm{V}_{\text {MOSA }}$. The line voltage $\mathrm{V}_{\mathrm{DC}}$ at this interruption state is expressed in (4).

$$
\begin{aligned}
\mathrm{V}_{\mathrm{DC}} & =\frac{1}{1.10}\left[\frac{\mathrm{di}}{\mathrm{dt}}\left(\mathrm{L}_{\mathrm{R}}\right)+\mathrm{V}_{\mathrm{MOSA}}\right] \\
\frac{\mathrm{di}}{\mathrm{dt}} & =\frac{1.10\left(\mathrm{~V}_{\mathrm{DC}}\right)}{\mathrm{L}_{\mathrm{R}}}-\mathrm{V}_{\mathrm{MOSA}}
\end{aligned}
$$

$\mathrm{T}_{\mathrm{MOSA}}$ is the time required by H-DCCB to suppress the maximum DC fault current $\left(\mathrm{I}_{\mathrm{f}(\max )}\right)$ to zero and is determined by (6). This time depends on factors like the clamping voltage of the MOSA, system voltage rating, the current limiting reactor $\left(\mathrm{L}_{R}\right)$ value, and resistance between the fault and breaker $\left(\mathrm{R}_{1}\right)$.

$$
\mathrm{T}_{\mathrm{MOSA}}=\frac{\mathrm{L}_{\mathrm{R}}}{\mathrm{R}_{\mathrm{F}}} \ln \left[1+\frac{\mathrm{R}_{1}}{\mathrm{~V}_{\mathrm{MOSA}}-\mathrm{V}_{\mathrm{DC}}} \mathrm{I}_{\mathrm{f}(\max )}\right]
$$

Therefore, the total energy dissipated, $\mathrm{E}_{\mathrm{MOSA}}$, by the arrestors during its conduction time is represented by (7) [21]:

$$
\mathrm{E}_{\mathrm{MOSA}}=\int_{0}^{\mathrm{T}_{\mathrm{MOSA}}}\left(\mathrm{V}_{\mathrm{MOSA}} \mathrm{I}_{\mathrm{MOSA}}\right) \mathrm{dt}
$$

It can be deduced from the (6) and (7) that decreasing the voltage rating of MOSA will increase its energy absorption capability. However, this leads to a longer current supersession time [45]. Therefore, the rated energy dissipation value of the arrestor must be higher than EMOSA.

Hence in an H-DCCB connected within the M-HVDC grid, the voltage rating of the MOSA can be made higher, well within the withstanding capability of the IGBT valves. This results in rapid fault current suppression, ultimately reducing the energy stresses on the MOSA [46]. 


\subsection{Thermal Stresses on Press-Pack IGBT Module}

In an H-DCCB, LCS is responsible for conducting current during normal load conditions and conducting a low magnitude short duration fault current just at the instance of fault inception before it is eventually opened. Therefore, it is incorporated with a watercooling system in this study. In contrast, the MB only conducts a high magnitude fault current for a time interval equal to the opening time of the UFA, which is around $2 \mathrm{~ms}$ [15]. Hence, an air-cooling system is used for heat dissipation in the MB valves during this period. This results in a difference in the junction temperature for the IGBT modules located in the LCS and UFA.

For a modern VSC-HVDC system, press-pack IGBT technology is more attractive than conventional IGBT module technology due to various advantages, as presented in [42]. Therefore, this technology is used in this study. The thermal model of a single press-pack IGBT module with a double-sided cooling system is used in H-DCCB, as shown in Figure 6. The power dissipated through the IGBT valves, and the corresponding free-wheeling diode is represented as $P_{V}$ and $P_{D}$, respectively. The IGBT chip thermal impedances between junction to collector and junction to emitter surfaces are defined as $Z_{\text {th(J-C) }}$ and $Z_{\text {th(J-E) }}$, respectively. In contrast, $Z_{\mathrm{th}(\mathrm{J}-\mathrm{K})}$ and $Z_{\mathrm{th}(\mathrm{J}-\mathrm{A})}$ are the thermal impedances between junction to cathode and junction to anode surface of diode. $Z_{\mathrm{th}(\mathrm{HS})}$ is the thermal impedance between the module case (body) and the heat sink. This is the same for both IGBT and diode sides [42]. The junction and case (body) temperature at each emitter and collector side is denoted as $\mathrm{T}_{\mathrm{V}-\mathrm{J}}$. In contrast, $\mathrm{T}_{\mathrm{D}-\mathrm{J}}$ is the junction and module case temperature between the cathode and the anode side of the diode. Lastly, $\mathrm{T}_{\mathrm{HS}}$ represents the heat sink temperature of the press-pack IGBT module.

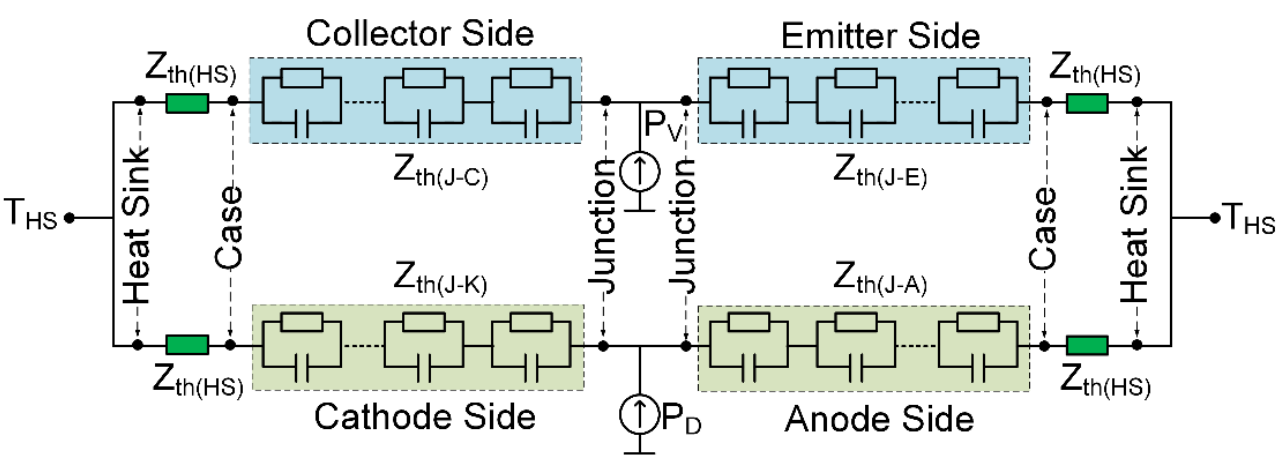

Figure 6. Equivalent thermal model of individual press-pack IGBT module.

For the sake of simplicity, it is assumed that all the thermal impedances between the junction and case for both the IGBT chip and diode are represented as $\mathrm{Z}_{\mathrm{th}(\mathrm{V}-\mathrm{JC})}$ and $\mathrm{Z}_{\mathrm{th}(\mathrm{D}-\mathrm{JC})}$. The typical values of the $Z_{\mathrm{th}(\mathrm{V}-\mathrm{JC})}$ and $\mathrm{Z}_{\mathrm{th}(\mathrm{D}-\mathrm{JC})}$ are $4 \mathrm{mK} / \mathrm{W}$, whereas $\mathrm{Z}_{\mathrm{th}(\mathrm{V}-\mathrm{CH})}$ and $\mathrm{Z}_{\mathrm{th}}(\mathrm{D}-\mathrm{CH})$ are $0.001 \mathrm{~K} / \mathrm{W}$ [42].

During a typical current interruption scenario, the switching losses of IGBT valves in MB and LCS can be ignored, and only the conduction losses are considered. Assuming that the entire fault current passes through the IGBT valve, the average conduction losses, $\mathrm{P}_{\mathrm{L}}$ can be determined using (8):

$$
\mathrm{P}_{\mathrm{L}}=\mathrm{V}_{\text {ce(on) }} \mathrm{I}_{\text {avg }}+\mathrm{R}_{\text {on }} \mathrm{I}_{\text {avg }}^{2}
$$

In (8), $\mathrm{V}_{\text {ce(on) }}$ is IGBT on-state voltage, $\mathrm{I}_{\text {avg }}$ is the average current passing through LCS, and $R_{\text {on }}$ is the on-state resistance of the IGBT module. Under normal conditions, the average load current passing through the $\mathrm{H}-\mathrm{DCCB}$ when connected in a four-terminal HVDC test system is $1.8 \mathrm{kA}$. Additionally, $\mathrm{R}_{\text {on }}$ and $\mathrm{V}_{\text {ce(on) }}$ are approximately $1.44 \mathrm{~m} \Omega$ and $2.6 \mathrm{~V}$, respectively [42]. As it is supposed that LCS is composed of a $3 \times 3$ IGBT matrix, and considering equal load sharing among each IGBT valve, the average load current is passing 
through each IGBT unit branch, $\mathrm{I}_{\text {avg }}$ is $0.60 \mathrm{kA}$. The average power loss of individual IGBT valves in LCS is thus determined to be approximately $2 \mathrm{~kW}$.

The IGBT valves of the LCS are forcibly cooled and kept at $36{ }^{\circ} \mathrm{C}$. Therefore, the heatsink temperature is assumed to be always $36^{\circ} \mathrm{C}$. From (9), the junction temperature is found to be around $46^{\circ} \mathrm{C}$. Indeed, the junction temperature of the IGBT module is well below its maximum temperature limit of $125^{\circ} \mathrm{C}$ [42].

$$
\mathrm{T}_{\mathrm{J}}=\mathrm{P}_{\mathrm{L}}\left(\mathrm{Z}_{\mathrm{th}(\mathrm{V}-\mathrm{JC})}+\mathrm{Z}_{\mathrm{th}(\mathrm{V}-\mathrm{CH})}+\right) \mathrm{T}_{\mathrm{HS}}
$$

Suppose that, during a DC fault, the heat generated due to the conduction losses in the IGBT module is not continuously dissipated due to variation in the heatsink temperature. In that case, the IGBT module temperature may rise above the rated value. This increases the thermal resistance of the IGBT chip in the module and decreases valve conductivity [47].

\section{Results and Discussion}

As illustrated in Figure 1, a four-terminal test system is developed in PSCAD/EMTDC to study and evaluate the electrical and thermal stresses on the IGBT valves and energy absorbed by the surge arrestors within H-DCCB during different $D C$ fault current scenarios. $\mathrm{H}-\mathrm{DCCB}$, as proposed by $\mathrm{ABB}$, is used in the simulation study. Current limiting reactors are added in a series of H-DCCB to limit the DC fault current for effective H-DCCB operation [41]. Employed parameters of the four-terminal test system and H-DCCB are enlisted in Tables 1 and 2, respectively.

The developed test system is assessed/tested for two types of protection levels: gridlevel and self-level protections to evaluate the electrical and thermal stresses imposed on the H-DCCB by the M-HVDC grid system. The study of stresses associated with driver-level protection is intended to be carried out in the future.

\subsection{Grid-Level Protection}

Under normal operating conditions, a trip signal to hybrid breaker is provided externally through a dedicated HVDC protection system [1]. The protection system monitors various M-HVDC grid parameters and issues a trip command to H-DCCB in case of any fault occurrence. H-DCCB initiates the tripping sequence on receiving the external trip sequence from the M-HVDC protection system.

\subsubsection{Low Impedance Fault Current Interruption}

Simulation results of H-DCCB on receiving the trip signal from the grid-level protection scheme are shown in Figure 7. At $\mathrm{t}=1.5 \mathrm{~s}$, a low impedance fault is applied at VSC4 , causing a high DC fault current to flow. The DC grid-level protection scheme issues a trip command with a delay of $6 \mathrm{~ms}$ to ensure that the DC fault current reaches the rated breaker current of $11.5 \mathrm{kA}$. The fault current, in this case, is well beyond the $9 \mathrm{kA}$, which is the interruption capability for H-DCCB as proposed by ABB [15]. Thus, by delaying the grid signal, maximum electrical and thermal stresses within the breaker rated limits can be exerted on the breaker components to visualize the effects of practical grid delays in the DC grid.

However, practically, the trip command is issued much sooner to extinguish the fault current safely well below the rated value of the breaker, $11.5 \mathrm{kA}$ in this study. Additionally, the self-level protection of the H-DCCB is disabled as it may issue a trip command below $90 \%$ of the rated current value of the breaker.

The respective currents flowing through the load, $\mathrm{MB}$, and energy absorption branches of the H-DCCB are shown in Figure 7a. It should be noted that the commutation of the fault current from the LCS to MB branch occurs when grid trip signal is zero, as well as when the LCS is opened. Afterward, the MB is only opened after the UFA is fully opened. The fault current then commutates to the MOSA branch before being extinguished. The IGBT valves of MB must bear greater current stress than the LCS valves as they are responsible for conducting the peak fault current. 

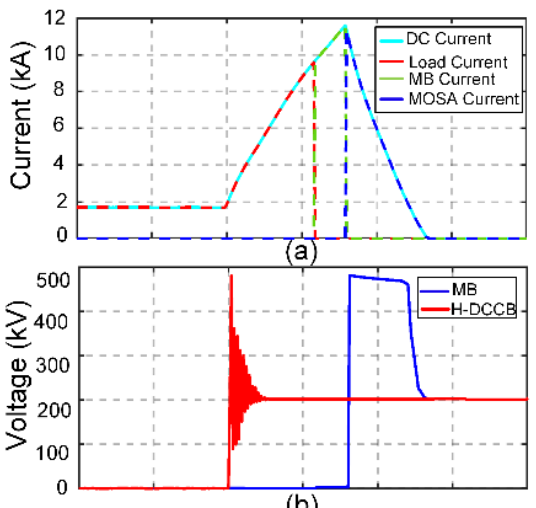

(b)
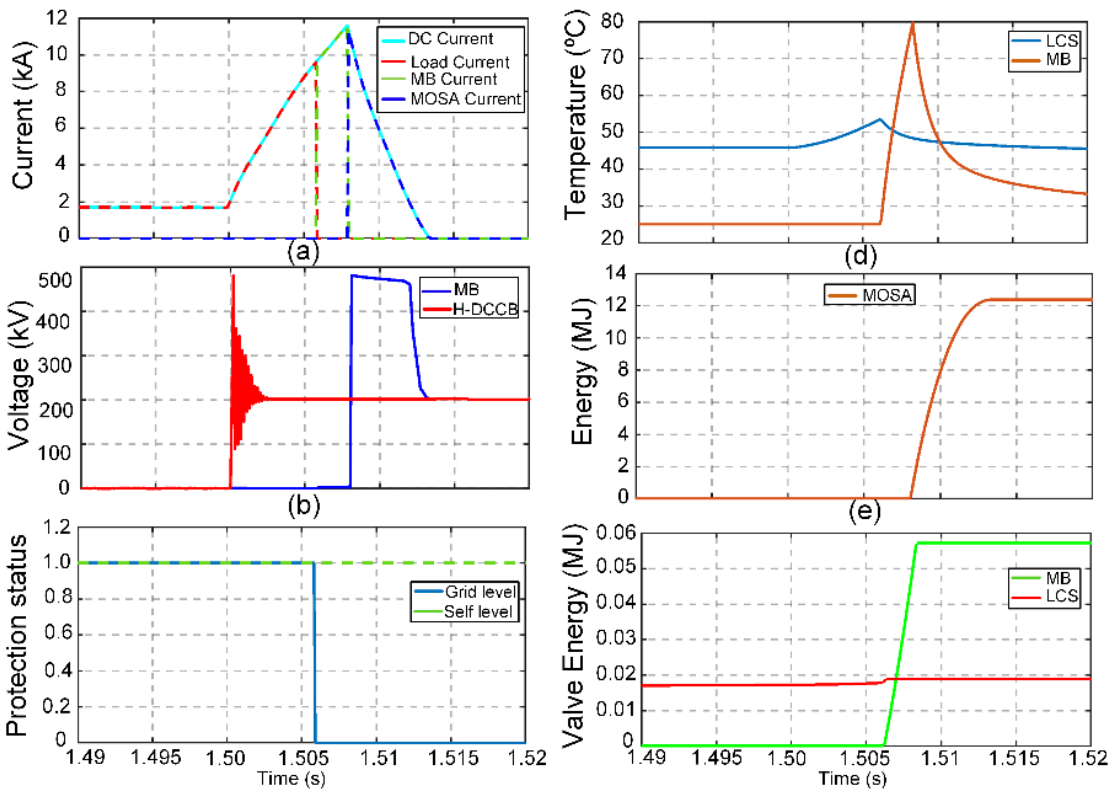

(c)

(f)

Figure 7. Low impedance fault interruption under grid-level protection, (a) current (b) voltage, (c) protection status, (d) valve temperature, (e) MOSA energy, (f) valve energy.

The IGBT junction temperature for both LCS and MB is shown in Figure 7d. It is assumed that the LCS valves are water-cooled at $40{ }^{\circ} \mathrm{C}$. In contrast, the MB valves are air-cooled as they are only responsible for conducting the transient fault current for a short time, around $2 \mathrm{~ms}$ only. The ambient air temperature is set to $20^{\circ} \mathrm{C}$ for $\mathrm{MB}$ valves in this study. The pre-fault temperature of the LCS valve is seen to be only $10^{\circ} \mathrm{C}$ greater than the coolant temperature, due to the $3 \times 3$ configuration of the IGBT valves in the LCS. This divides the current in each branch equally, leading to a small power loss in individual IGBT valves. The LCS valve temperature increases to just $53^{\circ} \mathrm{C}$, compared to a sharp rise in the $\mathrm{MB}$ valve temperature to around $80^{\circ} \mathrm{C}$. Still, the $\mathrm{MB}$ valve temperature does not exceed its maximum temperature limit of $125^{\circ} \mathrm{C}$ [42].

The energy dissipated across the LCS, and MB valves is shown in Figure 7e. It can be observed that the thermal stress in terms of energy dissipation across the IGBT valve of MB is comparatively greater than that of LCS. This is because the MB valves are responsible for handling the peak fault current for a short time before transferring to the MOSA branch. However, it is evident from Figure $7 \mathrm{f}$ that the MOSA branch is primarily responsible for neutralizing the fault current, as a large amount of energy is dissipated through this branch, around $12.4 \mathrm{MJ}$.

\subsubsection{High Impedance Fault Current Interruption}

A high impedance fault causes a relatively lower fault current than the rated current of the H-DCCB, $11.5 \mathrm{kA}$. Self-level protection of the breaker is disabled to observe the thermal stresses on the IGBT valves. A high impedance fault occurs at $t=1.5 \mathrm{~s}$, and the tripping threshold is set to $4 \mathrm{kA}$. The corresponding current waveforms are shown in Figure 8a. Both electrical and thermal stresses on the breaker components are reduced due to a decrease in the fault current magnitude. The maximum current passing through the LCS is around $4 \mathrm{kA}$, whereas the MB valves face up to $5.55 \mathrm{kA}$ current. Due to a decreasing fault current magnitude, both LCS and MB valves undergo reduced thermal stresses, as shown in Figure 8d. A slight temperature variation in the LCS valve is observed, whereas the temperature of the $\mathrm{MB}$ valves reaches a peak of around $39^{\circ} \mathrm{C}$. Additionally, the energy dissipation of the LCS valve is almost $17 \mathrm{~kJ}$, which is slightly greater than that of the MB valves. However, the IGBT valve energy dissipation value is negligible compared to the $2.58 \mathrm{MJ}$ of energy dissipation through MOSAs, as shown in Figure 8. 

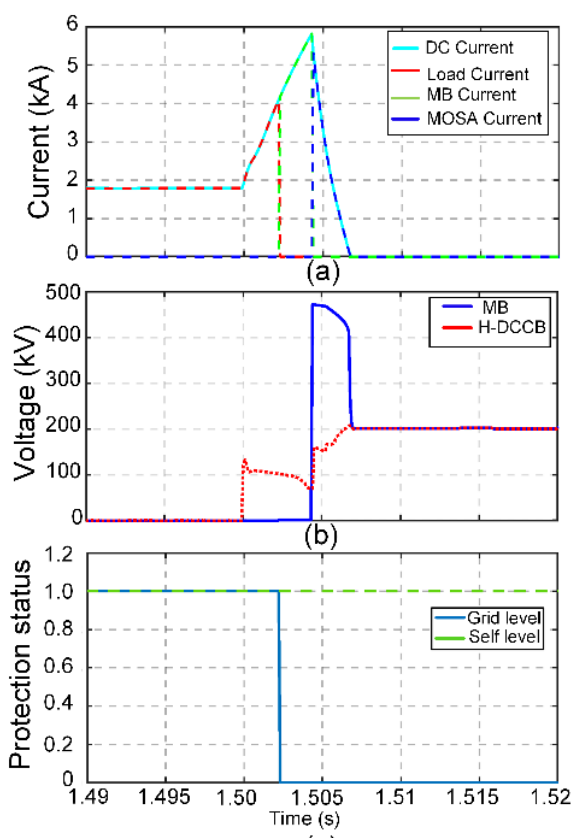

(c)
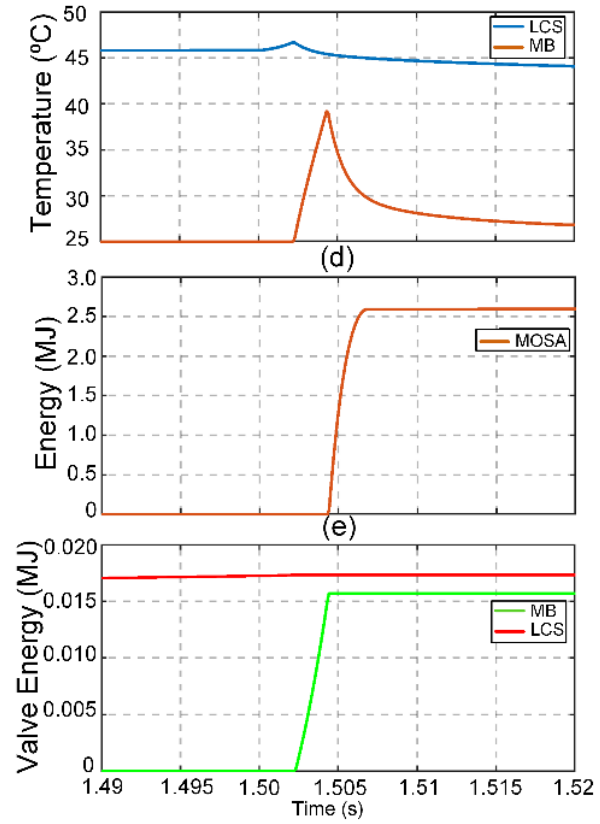

(f)

Figure 8. High impedance fault interruption under grid-level protection, (a) current (b) voltage, (c) protection status, (d) valve temperature, (e) MOSA energy, (f) valve energy.

\subsection{Self-Level Protection}

HVDC grid protection methods may rely on local measurements and information from both ends of the DC line. Various DC grid protection strategies are in practice, such as over-current and under-voltage protection [48], the ratio of transient voltage (ROTV) at the converter and line side $[49,50]$, as well as the rate of change of voltage (ROCV) across the current limiting inductor [45]. Still, no matter how advanced and reliable a grid protection strategy is, there is always a chance of failure.

Therefore, in future M-HVDC grids, breaker testing must be done for grid-level protection failure. In such a scenario, the H-DCCB may be exposed to high DC fault currents without any trip signal being initiated from the grid protection system. Therefore, if the self-level protection of the H-DCCB is not activated in a timely fashion, it ultimately leads to thermal breakdown and destruction of the M-HVDC.

\subsubsection{Low Impedance Fault Current Interruption}

Simulation results for low impedance fault current under self-protection are shown in Figure 9. Grid-level protection is disabled (Grid Order $=1$ ) as shown in Figure 9c. At $\mathrm{t}=1.5 \mathrm{~s}$, a low impedance high current fault is induced. The self-protection system of the H-DCCB monitors the load current and initiates the self-level protection (SP Order $=1$ ) at $t=1.504 \mathrm{~s}$ as seen in Figure 9c. This causes LCS to operate such that the peak fault current can only reach $90 \%$ of its rated interrupting current, that is $10.3 \mathrm{kA}$ as shown in Figure $9 \mathrm{a}$. The duration of voltage stress appearing on the IGBT valves and MOSAs in case of low impedance fault under self-protection is greater as compared to fault interruption under grid level protection as shown in Figure 9b.

The temperature of the IGBT valves is illustrated in Figure 9d. LCS and MB valves attain a peak temperature of $50.5^{\circ} \mathrm{C}$ and $66^{\circ} \mathrm{C}$, respectively. Like the low impedance fault under grid-level protection, the IGBT valves of $\mathrm{MB}$, in this case, attain a higher temperature than the LCS valves. However, as the self-level protection system of the DCCB opens the LCS at $8 \mathrm{kA}$, the corresponding temperature peaks of LCS and MB are lower in selflevel protection scenario than in the case of grid-level protection. In addition, the energy absorbed by the MOSAs is $2.25 \mathrm{MJ}$, as shown in Figure 9e. The combined energy dissipated by IGBT valves is far less than the energy dissipated by the surge arrestors as shown in 
Figure 9f. This is because only a small number of IGBT valves are used in LCS as well as turning-on of the MB valves at the time of commutation of current only.
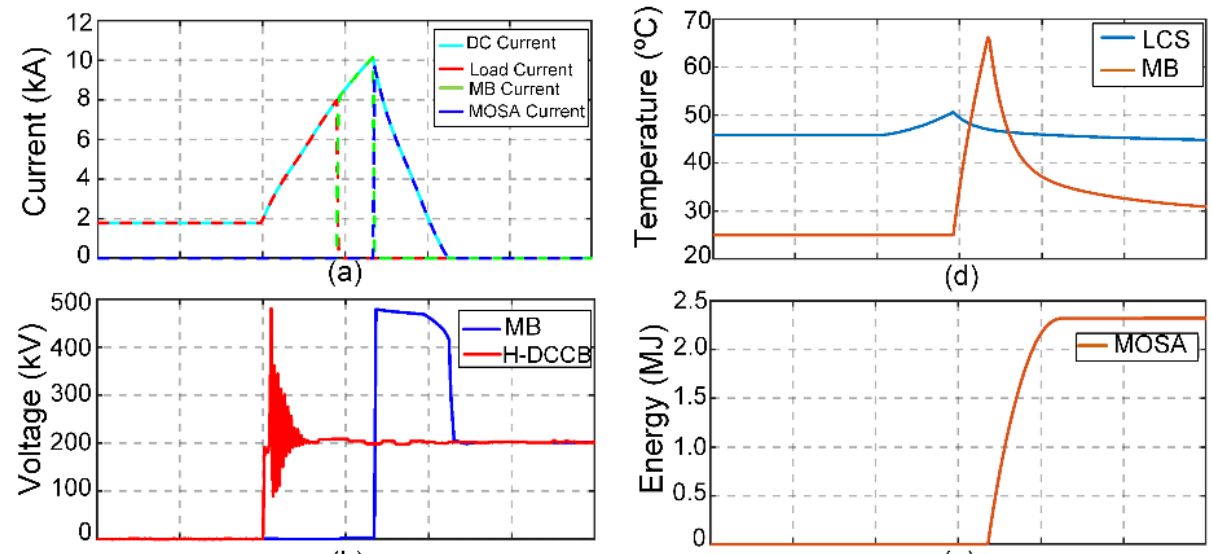

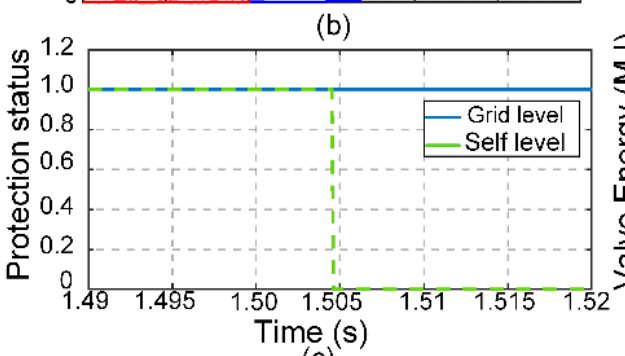

(c)

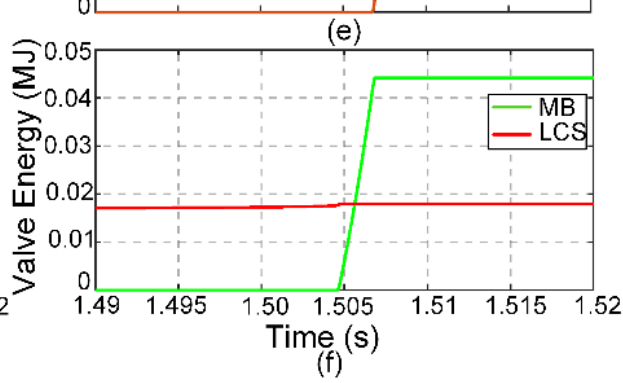

Figure 9. Low impedance fault interruption under self-level protection, (a) current (b) voltage, (c) protection status, (d) valve temperature, (e) MOSA energy, (f) valve energy.

\subsubsection{High Impedance Fault Current Interruption}

In a high impedance fault, the fault current is lower than the rated interrupting threshold current of the breaker. The thermal management system incorporated in LCS monitors IGBT valve temperature. In this case, a trip command is issued if the temperature exceeds a pre-defined threshold of $60^{\circ} \mathrm{C}$ as illustrated is Figure 10c.

At $=1.5 \mathrm{~s}$, a high impedance fault is applied, and the corresponding current waveforms are shown in Figure 10a. As expected, it is observed that the fault current magnitude is lesser than the rated interrupting current, at $11.5 \mathrm{kA}$. However, in contrast to the high impedance fault under grid-level control, the trip command is delayed until the LCS valves reach a threshold temperature of $60^{\circ} \mathrm{C}$ as seen in Figure 10d. This causes a considerable delay before the LCS can be opened. The LCS opens when the self-level protection is activated $(\mathrm{SP}=0)$, and the fault current commutes to the $\mathrm{MB}$. This causes a momentary rise in MB valve temperature, and it rises to $42^{\circ} \mathrm{C}$ only, as shown in Figure $10 \mathrm{~d}$.

Once the UFA has fully opened, the MB turns off, and the fault current is finally neutralized in the energy absorption branch by dissipating $0.46 \mathrm{MJ}$ energy only as seen in Figure 10e. It is also seen from Figure 10f that the energy dissipated through the LCS valve is higher than the MB valve due to the delayed operation of the H-DCCB. However, this energy dissipation stress is still significantly lower than the MOSA energy. Lastly, the duration of the voltage stress due to the TIV imposed by the MOSA branch is the smallest in this case as shown in Figure 10b.

By assessing the stresses imposed on H-DCCB as proposed by ABB in the M-HVDC system, it can be concluded that the ABB H-DCCB can reliably be used in future MHVDC grids. 

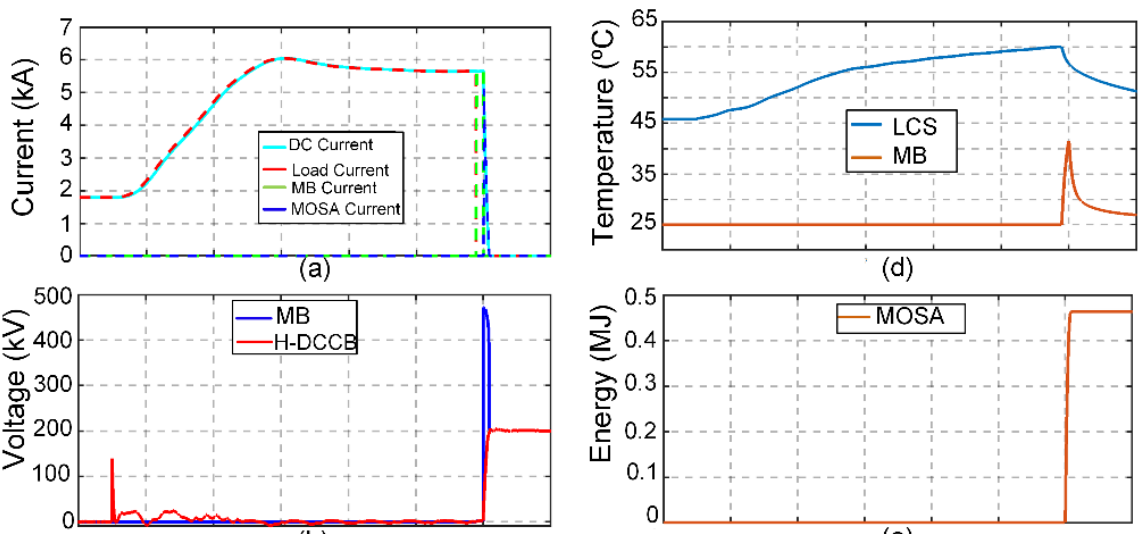

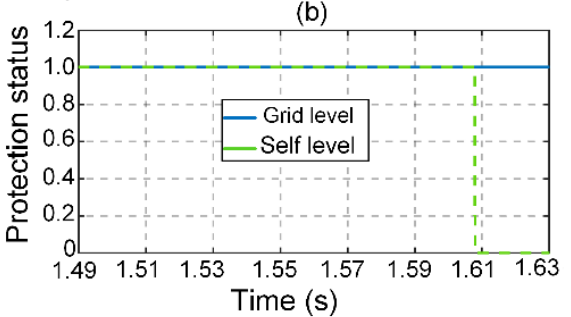

(c)

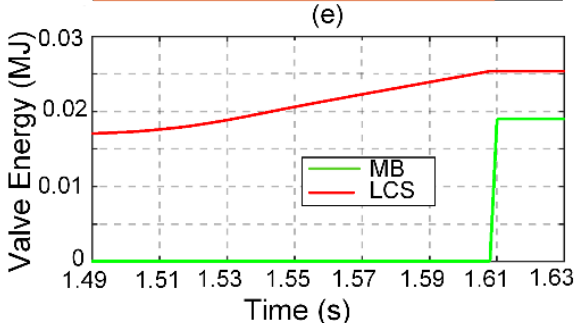

(f)

Figure 10. High impedance fault interruption under self-level protection, (a) current (b) voltage, (c) protection status, (d) valve temperature, (e) MOSA energy, (f) valve energy.

\section{Conclusions}

In this paper, the impacts of the M-HVDC grid on the operational parameters of the hybrid HVDC circuit breakers are assessed. Simulations were developed for a four-terminal HVDC system in PSCAD/MTDC with $12 \mathrm{H}$-DCCBs. A range of DC fault scenarios were presented, and operational parameters were evaluated, e.g., electrical, and thermal stresses on the IGBT valves of H-DCCB. From rigorous simulations, it was concluded that the worst fault scenario is the low impedance fault under the grid-level protection scheme. However, under a self-protection scheme, the IGBT valves undergo maximum thermal stress for a comparatively long duration during a high impedance fault current interruption. Therefore, the cooling mechanism of the IGBT valves in LCS must not fail, especially under this type of fault. Lastly, the IGBT valves of MB experience prolonged voltage stress due to TIV imposed by the MOSA branch under low impedance fault scenarios compared to high impedance faults.

Author Contributions: Conceptualization, A.R. and S.K.; methodology, A.R. and S.K.; formal analysis, A.R., S.K., U.A., G.A. and M.J.; investigation, U.A., M.Z.Y. and N.S.; resources, U.A. and N.S.; data curation, A.R., S.K., M.Z.Y., M.J. and G.A.; writing-original draft preparation, A.R., S.K. and G.A.; writing-review and editing, U.A., M.Z.Y., G.A., M.J. and N.S.; funding acquisition, U.A. and N.S. All authors have read and agreed to the published version of the manuscript.

Funding: This research received no external funding.

Institutional Review Board Statement: Not applicable.

Informed Consent Statement: Not applicable.

Data Availability Statement: Not applicable.

Conflicts of Interest: The authors declare no conflict of interest. 


\section{References}

1. Raza, A.; Akhtar, A.; Jamil, M.; Abbas, G.; Gilani, S.O.; Yuchao, L.; Khan, M.N.; Izhar, T.; Dianguo, X.; Williams, B.W.; et al. A Protection Scheme for Multi-Terminal VSC-HVDC Transmission Systems. IEEE Access 2018, 6, 3159-3166. [CrossRef]

2. Muniappan, M. A comprehensive review of DC fault protection methods in HVDC transmission systems. Prot. Control Mod. Power Syst. 2021, 6, 1-20. [CrossRef]

3. Barnes, M.; Vilchis-Rodriguez, D.S.; Pei, X.; Shuttleworth, R.; Cwikowski, O.; Smith, A.C. HVDC Circuit Breakers-A Review. IEEE Access 2020, 8, 211829-211848. [CrossRef]

4. Liu, Y.; Jin, Y.; Li, Z.; Liu, Y.; Li, B.; Duan, Z. Mechanical DC Breakers and Hybrid MMC Based Coordinated Strategy for MMC-HVDC DC Fault Riding Through. IEEE J. Emerg. Sel. Top. Power Electron. 2021. [CrossRef]

5. Liu, F.; Liu, W.; Zha, X.; Yang, H.; Feng, K. Solid-State Circuit Breaker Snubber Design for Transient Overvoltage Suppression at Bus Fault Interruption in Low-Voltage DC Microgrid. IEEE Trans. Power Electron. 2017, 32, 3007-3021. [CrossRef]

6. Stumpe, M.; Tünnerhoff, P.; Dave, J.; Schnettler, A.; Ergin, D.; Schoen, A.; Würflinger, K.; Schettler, F. DC fault protection for modular multi-level converter-based HVDC multi-terminal systems with solid-state circuit breakers. IET Gener. Trans. Distrib. 2018, 12, 3013-3020. [CrossRef]

7. Ludin, G.A.; Amin, M.A.; Matayoshi, H.; Rangarajan, S.S.; Hemeida, A.M.; Takahashi, H.; Senjyu, T. Solid-State DC Circuit Breakers and Their Comparison in Modular Multilevel Converter Based-HVDC Transmission System. Electronics 2021, 10, 1204. [CrossRef]

8. Hafner, J.; Jacobson, B. Proactive hybrid HVDC breakers-A key innovation for reliable HVDC grid. In Proceedings of the Electric Power System of the Future-Integrating Supergrids and Microgrids, Cigre Symposium, Bologna, Italy, 13-15 September 2011; pp. 264-272.

9. Zhou, W.; Wei, X.; Zhang, S.; Tang, G.; He, Z.; Zheng, J.; Dan, Y.; Gao, C. Development and test of a 200kV full-bridge based hybrid HVDC breaker. In Proceedings of the 17th European Conference on Power Electronics and Applications (EPE'15 ECCE-Europe), Geneva, Switzerland, 8-10 September 2015; pp. 1-7.

10. Bösche, D.; Wilkening, E.; Köpf, H.; Kurrat, M. Hybrid DC Circuit Breaker Feasibility Study. IEEE Trans. Compon. Packag. Manuf. Technol. 2017, 7, 354-362. [CrossRef]

11. Rao, H.; Zhou, Y.; Zou, C.; Xu, S.; Li, Y.; Yang, L.; Huang, W. Design aspects of hybrid HVDC system. CSEE J. Power Energy Syst. 2021, 7, 644-653.

12. Abedrabbo, M.; Leterme, W.; Hertem, D.V. Impact of operational parameters on HVDC circuit breaker requirements. In Proceedings of the CIGRE-IEC 2019 Conference on EHV and UHV (AC \& DC), Hakodate, Japan, 23-26 April 2019 ; p. 9.

13. Raza, A.; Mustafa, A.; Alqasemi, U.; Rouzbehi, K.; Muzzammel, R.; Guobing, S.; Abbas, G. HVdc Circuit Breakers: Prospects and Challenges. Appl. Sci. 2021, 11, 5047. [CrossRef]

14. Xiao, H.; Xu, Z.; Xiao, L.; Gan, C.; Xu, F.; Dai, L. Components Sharing Based Integrated HVDC Circuit Breaker for Meshed HVDC Grids. IEEE Trans. Power Deliv. 2020, 35, 1856-1866. [CrossRef]

15. Callavik, M.; Blomberg, A.; Hafner, J.; Jacobson, B. Break-through! ABB's hybrid HVDC breaker, an innovation breakthrough enabling reliable HVDC grids. Abb. Rev. 2012, 2, 7-13.

16. Grieshaber, W.; Dupraz, J.-P.; Panache, D.-L.; Violleau, L. Development and test of a $120 \mathrm{kV}$ direct current circuit breaker. CIGRE Paris 2014, 1-11, Paper B4-301.

17. Zheng, X.; Jia, R.; Gong, L.; Zhang, G.; Pei, X. An optimized coordination strategy between line main protection and hybrid dc breaker for VSC-based dc grid using overhead transmission line. Energies 2002, 12, 1462. [CrossRef]

18. An, T.; Tang, G.; Wang, W. Research and application on multi-terminal and DC grids based on VSC-HVDC technology in China. High Volt. 2017, 2, 1-10. [CrossRef]

19. Smeets, R. Safeguarding the Supergrid. IEEE Spectr. 2015, 52, 38-43. [CrossRef]

20. Shukla, A.; Demetriades, G.D. A Survey on Hybrid Circuit-Breaker Topologies. IEEE Trans. Power Deliv. 2014, $30,627-641$. [CrossRef]

21. Belda, N.A.; Smeets, R.P.P. Test Circuits for HVDC Circuit Breakers. IEEE Trans. Power Deliv. 2016, 32, 285-293. [CrossRef]

22. Tokuyama, S.; Arimatsu, K.; Yoshioka, Y.; Kato, Y.; Hirata, K. Development and Interrupting Tests on 250KV 8KA HVDC Circuit Breaker. IEEE Trans. Power Appar. Syst. 1985, 104, 2452-2459. [CrossRef]

23. Tamura, S.; Shimada, R.; Kito, Y.; Kanai, Y.; Koike, H.; Ikeda, H.; Yanabu, S. Parallel Interruption of Heavy Direct Current by Vacuum Circuit Breakers. IEEE Trans. Power Appar. Syst. 1980, 3, 1119-1129. [CrossRef]

24. Belda, N.A.; Plet, C.A.; Smeets, R.P.P. Full-Power Test of HVDC Circuit-Breakers with AC Short-Circuit Generators Operated at Low Power Frequency. IEEE Trans. Power Deliv. 2019, 34, 1843-1852. [CrossRef]

25. Gao, C.; Ding, X.; Tang, G.; Wang, G.; Qiu, P. Key stress extraction and equivalent test method for hybrid DC circuit breaker. Glob. Energy Interconnect. 2018, 1, 29-38.

26. Xu, Z.; Xiao, H.; Xu, Y. Two basic ways to realize DC circuit breakers. J. Eng. 2019, 2019, 3098-3105. [CrossRef]

27. Hofmann, G.; LaBarbera, G.; Reed, N.; Shillong, L.; Long, W.; Melvold, D. Field test of HVDC circuit breaker: Load break and fault clearing on the Pacific intertie. IEEE Trans. Power Appar. Syst. 1976, 95, 829-838. [CrossRef]

28. Melvold, D.; Shockley, P.; Long, W.; Hingorani, N. Three terminal operations of the Pacific HVDC intertie for dc circuit breaker testing. IEEE Trans. Power Appar. Syst. 1976, 95, 1287-1296. [CrossRef] 
29. Yanabu, S.; Tamagawa, T.; Irokawa, S.; Horiuchi, T.; Tomimuro, S. Development of HVDC Circuit Breaker and its Interrupting Test. IEEE Trans. Power Appar. Syst. 1982, 101, 1958-1965. [CrossRef]

30. Shimada, R.; Tani, K.; Kishimoto, H.; Tamura, S.; Ikeda, H.; Tamagawa, T.; Yanabu, S.; Matsushita, T. Synthetic test methods of high-direct-current circuit breaker. Proc. Inst. Electr. Eng. 1979, 126, 965-970. [CrossRef]

31. Sheng, B. A synthetic test circuit for current switching tests of HVDC circuit breakers. In Proceedings of the IEEE/PES Transmission and Distribution Conference and Exposition, Chicago, IL, USA, 21-24 April 2008.

32. Du, C.; Wang, C. Review of DC Circuit Breaker Technology for HVDC Application. In Proceedings of the 22nd International Conference on Electrical Machines and Systems (ICEMS), Harbin, China, 11-14 August 2019; pp. 1-6.

33. Leterme, W.; Ahmed, N.; Beerten, J.; Ängquist, L.; Hertem, D.V.; Norrga, S. A new HVDC grid test system for HVDC grid dynamics and protection studies in EMT-type software. In Proceedings of the 11th IET International Conference on AC and DC Power Transmission, Birmingham, UK, 10-12 February 2015.

34. Raza, A.; Dianguo, X.; Yuchao, L.; Xunwen, S.; Williams, B.W.; Cecati, C. Coordinated Operation and Control of VSC Based Multiterminal High Voltage DC Transmission Systems. IEEE Trans. Sustain. Energy 2016, 7, 364-373. [CrossRef]

35. Hock, P.; Belda, N.; Hinrichsen, V.; Smeets, R. Investigations on Metal-Oxide Surge Arresters for HVDC Circuit Breaker Applications. In Proceedings of the INMR World Congress, Tucson, AZ, USA, 20-23 October 2019.

36. Hesami, M.; Bakhshi, A.; Mousavi, S.; Rouzbehi, K.; Escaño, J.M. HVDC Breaker Power Loss Reduction by Bridge-Type Hybrid Breakers. Energies 2021, 14, 1526. [CrossRef]

37. Lin, W.; Jovcic, D.; Nguefeu, S.; Saad, H. Modelling of high-power hybrid DC circuit breaker for grid-level studies. IET J. Power Electron. 2016, 9, 237-246. [CrossRef]

38. Promotion EU Project. WP6, Deliverable 6.3. Develop a Real-Tme Component Level Model for Hybrid DC CB; PROMOTioN: Arnhem, The Netherlands, 2016.

39. Ito, H. HVDC Switching Equipment; CIGRE Green Books; Springer: Cham, Switzerland, 2019. [CrossRef]

40. Weiss, D.; Drack, N.; Maibach, P.; Kirchhoff, F.; Hassanpoor, A. Surge Arrester based Load Commutation Switch for Hybrid HVDC Breaker and MV DC Breaker; PCIM Europe: Nuremberg, Germany, 2018.

41. Hassanpoor, A.; Häfner, J.; Jacobson, B. Technical Assessment of Load Commutation Switch in Hybrid HVDC Breaker. IEEE Trans. Power Electron. 2015, 30, 5393-5400. [CrossRef]

42. Data Sheet. Doc. No. 5SYA 1431-02 01-2018. Available online: https://library.e.abb.com/public/8d0f218db8df4641a4bf7c978dd2 d239/5SNA\%202000K450300\%205SYA\%201431-02\%2001-2018.pdf (accessed on 1 January 2021).

43. Simpson, R.; Plumpton, A.; Varley, M.; Tonner, C.; Taylor, P.; Dai, X. Press-pack IGBTs for HVDC and FACTs. CSEE J. Power Energy Syst. 2017, 3, 302-310. [CrossRef]

44. Belda, N.A.; Plet, C.A.; Smeets, R.P.P. Analysis of Faults in Multiterminal HVDC Grid for Definition of Test Requirements of HVDC Circuit Breakers. IEEE Trans. Power Deliv. 2018, 33, 403-411. [CrossRef]

45. Sneath, J.; Rajapakse, A.D. Fault Detection and Interruption in an Earthed HVDC Grid Using ROCOV and Hybrid DC Breakers. IEEE Trans. Power Deliv. 2016, 31, 973-981. [CrossRef]

46. Geebelen, B.; Leterme, W.; Hertem, D.V. Analysis of DC breaker requirements for different HVDC grid protection schemes. In Proceedings of the 11th IET International Conference on AC and DC Power Transmission, Birmingham, UK, 10-12 February 2015.

47. Yu, A.P.; Guo, B.X.; Wang, C.L.; Zhou, D.Z.; Wang, E.G.; Zhang, F.Z. Lifetime estimation for hybrid HVDC breakers. Int. J. Electr Power Energy Syst. 2020, 120, 106035. [CrossRef]

48. Xiang, W.; Yang, S.; Xu, L.; Zhang, J.; Lin, W.; Wen, J. A Transient Voltage-Based DC Fault Line Protection Scheme for MMC-Based DC Grid Embedding DC Breakers. IEEE Trans. Power Deliv. 2019, 34, 334-345. [CrossRef]

49. Liu, J.; Ta, N.; Fan, C. Transient-Voltage-Based Protection Scheme for DC Line Faults in the Multiterminal VSC-HVDC System. IEEE Trans. Power Deliv. 2017, 32, 1483-1494. [CrossRef]

50. Wang, Y.; Hao, Z.; Zhang, B.; Kong, F. A Pilot Protection Scheme for Transmission Lines in VSC-HVDC Grid Based on Similarity Measure of Traveling Waves. IEEE Access 2019, 7, 7147-7158. [CrossRef] 